\title{
Effects of Cocaine on Epicardial Coronary Artery Reactivity in Miniature Swine after Endothelial Injury and High Cholesterol Feeding
}

\section{In Vivo and In Vitro Analysis}

Kensuke Egashira, Frank S. Pipers, “ and James P. Morgan

Charles A. Dana Research Institute and Harvard-Thorndike Laboratory of Beth Israel Hospital, and Cardiovascular Division, Department of Medicine, Beth Israel Hospital and Harvard Medical School, Boston, Massachusetts 02115; and School of Veterinary Medicine, * Tufts University, North Grafton, Massachusetts 01536

\begin{abstract}
The purpose of this study was to determine the effects of cocaine on vasoreactivity in the swine model. Eight miniature pigs underwent regional endothelial denudation of the left anterior descending coronary artery and were then fed a high cholesterol diet. Cross-sectional area (CSA) of coronary arteries was measured by quantitative angiography. Before denudation, intravenous cocaine $(1,3$, and $10 \mathrm{mg} / \mathrm{kg})$ decreased CSA of epicardial vessels by 19-44\%. At 3 mo after the denudation, the percent reduction in CSA of the denuded vessels induced by the 10 $\mathrm{mg} / \mathrm{kg}$ dose was significantly augmented compared to nondenuded vessels $(59 \pm 5 \%$ vs. $48 \pm 4 \%, P<0.05)$. Under in vitro conditions where isometric force of isolated ring segments was measured, methoxamine (an $\alpha_{1}$ agonist) or BHT-920 (an $\alpha_{2}$ agonist) produced similar degrees of contraction of denuded and control vessels; however, cocaine in concentrations up to 3 $\times 10^{-3} \mathrm{M}$ did not produce contraction. These responses were unaffected by removal of the endothelium. Histologically, myointimal thickening was noted at the denuded site. The present study demonstrates an enhanced vasoreactivity of atherosclerotic coronary arteries to cocaine in vivo, the mechanism of which appears to be mediated by endogenous vasoactive substances rather than by a direct action of cocaine on vascular smooth muscle. (J. Clin. Invest. 1991. 88:1307-1314.) Key words: atherosclerosis - cocaine - coronary circulation - coronary vasospasm $\cdot$ histamine
\end{abstract}

\section{Introduction}

As the recreational use of cocaine in the United States has reached epidemic proportions, recent clinical reports have linked the abuse of cocaine with the development of acute myocardial infarction (1-4). Although most investigators have proposed that cocaine provokes coronary vasospasm resulting in myocardial infarction $(3,4)$, few studies have been performed to test this hypothesis in humans or experimental animals. Of interest, a recent clinical study (5) in nonactive cocaine users showed a modest coronary vasoconstriction after intranasal administration of cocaine in a dose of $2 \mathrm{mg} / \mathrm{kg}$; none of the study subjects manifested any evidence of coronary vaso-

Address reprint requests to Dr. Morgan, Cardiovascular Division, Beth Israel Hospital, 330 Brookline Avenue, Boston, MA 02215.

Received for publication 14 February 1990 and in revised form 17 April 1991.

J. Clin. Invest.

(c) The American Society for Clinical Investigation, Inc.

$0021-9738 / 91 / 10 / 1307 / 08 \quad \$ 2.00$

Volume 88, October 1991, 1307-1314 spasm or myocardial ischemia. Thus, this clinical study appears to provide no definitive evidence for a putative role of cocaine in inducing coronary vasospasm. However, this study of necessity utilized a relatively low dose of cocaine rather than examining the full range of concentrations relevant to abusers, and could not directly address the question of the drug's effects on angiographically normal and atherosclerotic coronary arteries. These issues are more suitable for study in an animal model with coronary anatomy and responsiveness that are similar to those of human beings. Fortunately, the miniature swine model of coronary atherosclerosis and vasospasm that was originally developed in Japan (6-10) meets the necessary criteria for performing such a study; this model provides a means for testing the effects of cocaine on control and atherosclerotic (i.e., hyperreactive) vessels in the same heart.

In the present study, we determined the effects of cocaine on the reactivity of epicardial coronary arteries in miniature swine 3 mo after endothelial denudation of the coronary artery and high-cholesterol feeding. Our specific aims were $(a)$ to develop a comparable swine model of coronary vasospasm in our laboratory, $(b)$ to compare the constrictor responses of control and denuded coronary arteries to cocaine in vivo by means of coronary arteriography; and (c) to compare the isometric contractile force responses of isolated coronary arterial segments in vitro to test cocaine's direct actions on arterial tissues.

\section{Methods}

Animal preparation and hemodynamic measurement. Eight Yucatan miniature pigs (Charles River Breeding Laboratories, Inc., Wilmington, MA; 4-6 mo old and 20-24 kg in weight) were sedated with intramuscular ketamine hydrochloride $(12.5 \mathrm{mg} / \mathrm{kg})$ and were then anesthetized with $1.0-1.5 \%$ isoflurane. Under sterile conditions, the left carotid artery was exposed and an $8 \mathrm{~F}$ catheter (Kifa) was passed through this vessel to the orifice of the left coronary artery. Arterial pressure was measured through the lumen of the catheter with a pressure transducer (Statham). Electrocardiograms in leads I, II, $\mathrm{aV}_{\mathrm{F}}, \mathrm{V}_{1}$, and $\mathrm{V}_{6}$ were continuously monitored by use of a polygraph system (Gould, Inc., Cleveland, $\mathrm{OH}$ ) and recorded on a multichannel recorder. Arterial $\mathrm{pH}$, $\mathrm{PO}_{2}$, and $\mathrm{PCO}_{2}$ were kept within physiological ranges. Rectal temperature was held at $37.0-37.5^{\circ} \mathrm{C}$ with external heating pads. After blood was drawn for serum cholesterol measurement (enzymatic method), intravenous physiological saline $(50 \mathrm{ml} / \mathrm{h})$ and heparin $(5,000 \mathrm{U}$ bolus followed by $1,000 \mathrm{U} / \mathrm{h}$ ) infusion was started and continued throughout each angiographical experiment.

Endothelial denudation of the coronary artery and chronic cholesterol feeding. After the first angiographic study, denudation of the endothelium of the left anterior descending coronary artery (LAD) ${ }^{1}$ was performed as previously described (6-9). Briefly, a 2F balloon catheter

1. Abbreviations used in this paper: CSA, cross-sectional area; LAD, left anterior descending coronary artery; LCX, left circumflex artery. 
was advanced into the proximal portion of the LAD and endothelium was gently denuded by repeated inflation-deflation of the balloon. This technique causes no serious injury to arterial smooth muscle, but produces histologic evidence of atherosclerotic lesions within 3 mo $(6,7)$. After this procedure, animals were admitted to the intensive care unit of the New England Veterinary Medical Center, North Grafton, MA, for recovery. Antibiotics were administered, if prescribed by a veterinary physician (Dr. Pipers). After confirming that the animals had recovered from surgery and were afebrile, they were housed in a temperature-controlled animal ward and were fed Minipig Breeder Chow (Charles River Breeding Laboratories, Inc.) containing 2\% cholesterol and a mixture of milk, lard, peanut oil, and vitamins. The amount of the daily food intake was 3-5\% of the body weight.

Coronary arteriography and its analysis. Studies with selective coronary arteriography were performed before and 3 mo after denudation of coronary vessels. Coronary cineangiograms were obtained with a cineangiographic unit (Phillips Scientific, Mahwah, NJ). Iopamidol 76\% (Squibb Diagnostic, Princeton, NJ) was used as the contrast material. The image intensifier was positioned to obtain a right anterior oblique projection of the left coronary system. This position was kept constant throughout the experiment. The measurement of cross-sectional area (CSA) was performed as previously described $(7,8)$. Briefly, the denuded (LAD) and the nondenuded (the same anatomical portion of the left circumflex artery [LCX]) segments were selected on an enddiastolic frame and diameters were measured with digital calipers. The size of angiographic catheter was used as a reference standard, which allowed diameter to be calibrated in absolute values $(\mathrm{mm})$. CSA was then calculated from the diameters of the vessels $[C S A=3.14 \times($ vessel diameter $/ 2)^{2}$ ]. Percent changes of CSA were reported as follows: (CSA after nitroglycerin - CSA after cocaine)/CSA after nitroglycerin $\times 100(\%)$.

Isometric force recording under in vitro conditions. After completing the second angiographical studies, the heart was rapidly removed and the left coronary arterial system was isolated. One to three pairs of arterial rings, 2-3 $\mathrm{mm}$ in length, were prepared from the LAD (denuded site) and LCX (nondenuded site), and were mounted in organ bath chambers filled with $50 \mathrm{ml}$ of physiological salt solution (PSS) gassed with $95 \% \mathrm{O}_{2}-5 \% \mathrm{CO}_{2}$ at $37.5^{\circ} \mathrm{C}(\mathrm{pH} 7.3-7.4)$. The region of denudation was identified using reference branches obtained by reviewing coronary angiograms. Circular isometric force in these muscles was measured with force transducers (model UC-2, Gould, Inc.) and recorded on a thermal chart recorder (Gould, Inc.). After equilibration for $1 \mathrm{~h}$, resting tension was set to $2 \mathrm{~g}$. Muscles were then contracted with $60 \mathrm{mM}$ potassium chloride $(\mathrm{KCl})$ solution at 30 -min intervals, during which period the muscles were progressively stretched until contractile force reached the maximum level (i.e., $L_{\max }$ ).

After equilibration at $L_{\max }$ for $60 \mathrm{~min}$, the dose-response relationships for cocaine, methoxamine (an $\alpha_{1}$ agonist), BHT-920 (an $\alpha_{2}$ agonist), and histamine were constructed by cumulative addition of drugs. For normalization, responses to agonists were plotted as a percentage of the $60 \mathrm{mM} \mathrm{KCl}$ contraction. The composition of physiological salt solution was (mM) $\mathrm{NaCl} 120, \mathrm{KCl} 5.9$, dextrose 11.5, $\mathrm{NaHCO}_{3} 25$, $\mathrm{MgCl}_{2} 1.2, \mathrm{NaH}_{2} \mathrm{PO}_{4} 1.2$, and $\mathrm{CaCl}_{2}$ 2.5. The $60 \mathrm{mM} \mathrm{KCl}$ solution was made by replacing equimolar sodium chloride with $\mathrm{KCl}$.

Experimental protocol. Preliminary experiments showed that $>15$ $\mathrm{mg} / \mathrm{kg}$ of intravenous cocaine caused sustained hypotension and interrupted the animal's breathing pattern. Thus, the $10 \mathrm{mg} / \mathrm{kg}$ dose was chosen as maximal in our experiments.

The study was performed in two phases: studies under in vivo and in vitro conditions. First, an angiographic study was repeated before and $3 \mathrm{mo}$ after the denudation of the coronary artery. In each experiment, angiograms were obtained before and after intravenous nitroglycerin, $0.4 \mathrm{mg}$. $30 \mathrm{~min}$ after nitroglycerin was studied, the following two in vivo protocols were conducted in random order: protocol I (cocaine study) and protocol II (histamine study). A 60-min washout period was allowed to elapse between those two studies. Coronary arteriography was performed 1-2 min after histamine and 2-5 min after cocaine when hemodynamic variables recovered to the control levels or reached a plateau phase. In protocol I, intravenous cocaine in doses of 1,3 , and $10 \mathrm{mg} / \mathrm{kg}$ was administered at intervals of $10 \mathrm{~min}$, because cocaine in this range of doses produced sustained coronary vasoconstriction at least for $20 \mathrm{~min} .10 \mathrm{~min}$ after a $10 \mathrm{mg} / \mathrm{kg}$ dose of cocaine, saline (vehicle), and bunazosin (a selective $\alpha_{1}$ antagonist; see reference $24), 0.1 \mathrm{mg} / \mathrm{kg}$ i.v., were infused intravenously at a 5 -min interval, and coronary arteriography was then performed after the vehicle and bunazosin administration. We confirmed that bunazosin, $0.1 \mathrm{mg} / \mathrm{kg}$, inhibited the pressor response to intravenous methoxamine, $0.2 \mathrm{mg}$, from $+23 \pm 8$ to $+8 \pm 3 \mathrm{mmHg}(P<0.01)$. In protocol II, intracoronary histamine in doses of 1,3 , and $10 \mu \mathrm{g} / \mathrm{kg}$ and intracoronary histamine, 10 $\mu \mathrm{g} / \mathrm{kg}, 5 \mathrm{~min}$ after pretreatment with chlorpheniramine $\left(\mathrm{an}_{1} \mathrm{H}_{1}\right.$ receptor antagonist), $0.1 \mathrm{mg} / \mathrm{kg}$, were administered at $10-20$-minute intervals. The dose of $\mathrm{H}_{1}$ receptor antagonist was determined which significantly inhibited the constrictive responses of intact coronary arteries to histamine, $10 \mu \mathrm{g} / \mathrm{kg}$ (see Table I). Intracoronary histamine injection was completed in $1 \mathrm{~min}$ and the total volume of the injection was $1 \mathrm{ml}$. During the intracoronary infusion, care was taken to deliver equal amounts of the drug into the LAD and LCX. Second, after the end of those in vivo experiments, pigs were killed and coronary arteries were removed. They were then dissected free in a dish filled with oxygenated PSS for in vitro experiments.

Histologic analysis. Tissues were placed in buffered formalin for at least $48 \mathrm{~h}$, imbedded in paraffin, sectioned at $1-\mathrm{mm}$ intervals, and mounted on glass slides. The sections were stained with hematoxylin and eosin, and with Van Geisson elastic stain.

Drugs and chemicals. Methoxamine $\mathrm{HCl}$ (Burroughs Wellcome, Research Triangle Park, NC), BHT-920 (Boehringer Ingelheim Pharmaceuticals, Ridgefield, CT), histamine (Sigma Chemical Co., St. Louis, MO), cocaine $\mathrm{HCl}$ (Mallinkcrodt Chemicals, Inc., St. Louis, MO), chlorpheniramine (Sigma Chemical Co.), and bunazosin (Ei-Zai Pharmaceuticals, Tokyo, Japan) were used.

Statistical analysis. Data were expressed as mean \pm SEM. Statistical analysis of changes in body weight or total cholesterol level was performed by Student's $t$ test. When hemodynamic variables such as heart rate and arterial pressure were compared, one way analysis of variance (ANOVA) followed by a Bonferroni's multiple comparison test was used. For comparison of dose-response relationships of agonists and individual data points in vivo, multiway ANOVA of repeated measures followed by a Bonferroni's test was used (11). In addition, to test the hypothesis that vasoreactivity of the denuded LAD is enhanced compared with that of the LCX, multiple linear regression analysis was performed using dummy variables (12).

For comparison of a contractile response (isometric force) or $\mathrm{pD}_{2}\left[-\log \left(E D_{50}\right)\right]$ between arterial tissues isolated from LAD and LCX in vitro, Student's $t$ tests were used. The $\mathrm{ED}_{s 0}$ (an effective concentration of agonist required to cause $50 \%$ of the maximal constrictive response to the agonist) was calculated by a computerized nonlinear equation method. Probability of $<0.05$ was considered to be significant.

\section{Results}

Body weight, serum cholesterol level, and coronary diameter. Body weight increased significantly from $13.8 \pm 0.3$ to $26.0 \pm 0.6$ $\mathrm{kg}(P<0.01)$ and the total serum cholesterol level from $64 \pm 3$ (ranging $49-81$ ) to $265 \pm 19 \mathrm{mg} / \mathrm{dl}$ (ranging $180-383 \mathrm{mg} / \mathrm{kg})(P$ $<0.01$ ) during the 3 -mo period of high cholesterol feeding. No significant organic stenosis was detected angiographically at any site of the epicardial coronary tree in any of the animals.

Histamine study in vivo (Table I and Fig. 1). Vessel area and hemodynamic variables are summarized in Table I. Intracoronary injection of the saline had no effects on these variables. Before denudation, percent narrowing of CSA in response to histamine increased in a dose-dependent manner; however, no statistical difference was found in constrictive re- 


\begin{tabular}{|c|c|c|c|c|}
\hline & \multicolumn{2}{|c|}{ Percent reduction in CSA } & \multirow[b]{2}{*}{ MAP } & \multirow[b]{2}{*}{ HR } \\
\hline & $\begin{array}{l}\text { Denuded site } \\
\text { (LAD) }\end{array}$ & $\begin{array}{l}\text { Nondenuded site } \\
\text { (LCX) }\end{array}$ & & \\
\hline & & & $m m H g$ & bpm \\
\hline \multicolumn{5}{|l|}{ Before endothelial denudation } \\
\hline Baseline & $8 \pm 2$ & $7 \pm 1$ & $85 \pm 4$ & $98 \pm 6$ \\
\hline \multicolumn{5}{|l|}{ Histamine } \\
\hline $1 \mu \mathrm{g} / \mathrm{kg}(n=6)$ & $18 \pm 3$ & $22 \pm 2$ & $84 \pm 3$ & $105 \pm 4$ \\
\hline $3 \mu \mathrm{g} / \mathrm{kg}(n=6)$ & $31 \pm 3$ & $39 \pm 3$ & $86 \pm 3$ & $111 \pm 4$ \\
\hline $10 \mu \mathrm{g} / \mathrm{kg}(n=6)$ & $34 \pm 3$ & $40 \pm 3$ & $80 \pm 3$ & $104 \pm 6$ \\
\hline $10 \mu \mathrm{g} / \mathrm{kg}$ after chlorpheniramine $0.1 \mathrm{mg} / \mathrm{kg}(n=6)$ & $11 \pm 2^{8}$ & $13 \pm 2^{8}$ & $88 \pm 4$ & $106 \pm 4$ \\
\hline \multicolumn{5}{|l|}{3 mo after endothelial denudation } \\
\hline Baseline & $12 \pm 2$ & $14 \pm 2$ & $89 \pm 5$ & $101 \pm 8$ \\
\hline \multicolumn{5}{|l|}{ Histamine } \\
\hline $1 \mu \mathrm{g} / \mathrm{kg}(n=8)$ & $48 \pm 2^{*}$ & $30 \pm 5$ & $85 \pm 3$ & $112 \pm 3$ \\
\hline $3 \mu \mathrm{g} / \mathrm{kg}(n=8)$ & $71 \pm 3^{\ddagger}$ & $44 \pm 5$ & $84 \pm 2$ & $115 \pm 4$ \\
\hline $10 \mu \mathrm{g} / \mathrm{kg}(n=8)$ & $94 \pm 1^{\ddagger}$ & $42 \pm 5$ & $88 \pm 5$ & $110 \pm 5$ \\
\hline $10 \mu \mathrm{g} / \mathrm{kg}$ after chlorpheniramine $0.1 \mathrm{mg} / \mathrm{kg}(n=6)$ & $25 \pm 3^{\prime \prime}$ & $28 \pm 2^{\prime \prime}$ & $84 \pm 5$ & $114 \pm 5$ \\
\hline
\end{tabular}

Data are mean \pm SEM. Percent changes in CSA in response to histamine are shown. All values of percent CSA reduction after histamine were significantly different $(P<0.05)$ vs. value of baseline. Absolute values of the denuded and nondenuded sites are $3.9 \pm 0.3$ and $3.9 \pm 0.2 \mathrm{~mm}^{2}$ before endothelial denudation, and $5.3 \pm 0.4$ and $5.0 \pm 0.3 \mathrm{~mm}^{2} 3 \mathrm{mo}$ after the denudation, respectively. Abbreviations: MAP, mean arterial pressure; HR, heart rate; bpm, beats per minute. ${ }^{*} P<0.05{ }^{*} P<0.01$ vs. nondenuded site (LCX) by two-way ANOVA plus a Bonferroni test with 10 pairwise comparisons. ${ }^{8} P<0.05$; ${ }^{\|} P<0.01$ vs. before chlorpheniramine by two-way ANOVA plus a Bonferroni test with four pairwise comparisons.

sponses of the LAD and LCX. The maximum level of narrowing was $<50 \%$ on average.

3 mo after the endothelial denudation, coronary vasospasm occurred at the denuded coronary segments after intracoronary histamine administration in all eight pigs: serial angiograms from a representative experiment are demonstrated in Fig. 1. Percent reduction in CSA of the denuded (LAD) coronary arteries was significantly greater than those at the nondenuded (LCX) arteries after the 1,3 , and $10 \mu \mathrm{g} / \mathrm{kg}$ doses of histamine ( $P$ $<0.01$ by ANOVA plus a Bonferroni test). Arterial pressure transiently declined during the first $30 \mathrm{~s}$ of histamine injection and recovered to the control levels by $90 \mathrm{~s}$ (7), when coronary angiograms were obtained. Heart rate significantly increased after 1,3 , and $10 \mu \mathrm{g} / \mathrm{kg}$ of histamine. At a time when histamine-induced spasm was provoked, electrocardiograms showed significant ST segment shift from the baseline level over $0.2 \mathrm{mV}$ in six (four, ST elevation; two, ST depression) of the eight pigs. After $\mathrm{H}_{1}$ blockade with chlorpheniramine 0.1 $\mathrm{mg} / \mathrm{kg}$, histamine-induced coronary spasm was almost completely blocked, indicating the effectiveness of $\mathrm{H}_{1}$ receptor stimulation in inducing coronary spasm in this model.

Cocaine study in vivo (Table II, Figs. 2 and 3). Serial angiograms from the same pig as presented in Fig. 1 are shown in Fig. 2. Responses of hemodynamic variables and CSA to cocaine before and three months after endothelial denudation are shown in Table II and Fig. 3. Intravenous saline had no effect. Arterial pressures and heart rate increased progressively as doses of intravenous cocaine were increased; these hemodynamic responses were similar in the 0 - and 3-mo periods. Before the denudation procedure, CSA of the LAD and LCX decreased in a concentration-dependent manner after cocaine in doses of 1,3 , and $10 \mathrm{mg} / \mathrm{kg}$; there was no significant difference in vasoconstrictive responses between the LAD and LCX. 3 mo later, the cocaine-induced vasoconstriction was significantly enhanced in the LAD compared with the LCX $(P<0.01$ by two-way ANOVA and by multiple linear regression analysis), percent reductions in CSA of the denuded LAD site by 10 $\mathrm{mg} / \mathrm{kg}$ of cocaine were significantly larger than those of the nondenuded LCX site; $59 \pm 1$ vs. $48 \pm 2 \%(n=8 ; P<0.05$ by two-way ANOVA plus a Bonferroni test with 10 comparisons). By treatment with bunazosin after the $10 \mathrm{mg} / \mathrm{kg}$ dose of cocaine, cocaine-induced enhanced vasoconstriction of the denuded LAD was not inhibited $(n=6)$; the percent CSA reduction in LAD vs. LCX by $10 \mathrm{mg} / \mathrm{kg}$ was $61 \pm 2$ vs. $46 \pm 2 \%$ ( $P$ $<0.05)$, and $49 \pm 2$ vs. $33 \pm 1 \%(P<0.01)$, before and after bunazosin treatment, respectively. Before endothelial denudation, the effects of bunazosin on the response to cocaine were similar in LAD and LCX sites $(n=6)$; percent CSA reduction was $43 \pm 2$ vs. $44 \pm 2 \%$, and $35 \pm 3$ vs. $30 \pm 2 \%$, before and after bunazosin, respectively. Arterial pressure decreased and heart rate slightly increased after bunazosin treatment. When administered before bunazosin $(n=6)$, intravenous saline had no effects on coronary diameters and hemodynamics. Significant ST depression $(0.2 \mathrm{mV})$ occurred on the electrocardiograms after the $10 \mathrm{mg} / \mathrm{kg}$ dose of cocaine in six animals before endothelial denudation and in eight of the eight animals 3 mo later.

Isometric force recording in vitro (Table III). Maximal response of isometric force to agonists and $\mathrm{pD}_{2}$ values $(-\log$ $\left.\mathrm{ED}_{50}\right)$ are shown in Table III. There was no statistical difference in resting force or active contraction evoked by $60 \mathrm{mM}$ $\mathrm{KCl}$ solution between muscles isolated from the denuded and control sites. Methoxamine or BHT- 920 produced a modest 
CONTROL ANGIOGRAM

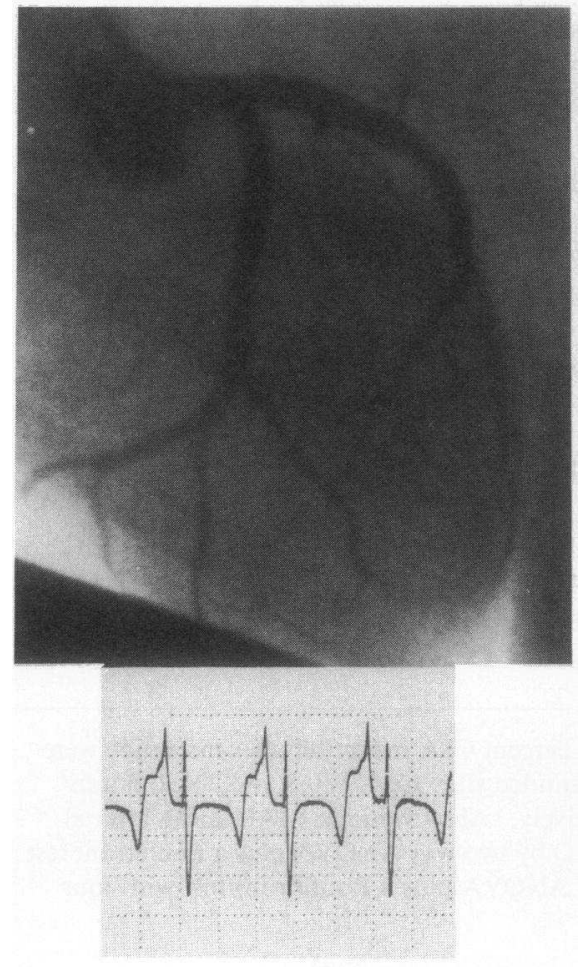

\section{AFTER HISTAMINE IC}

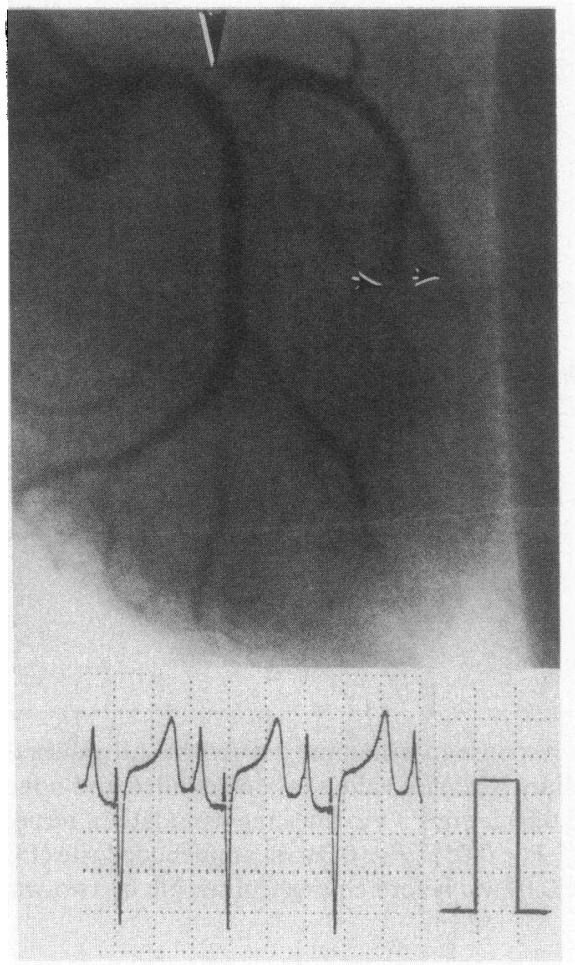

Figure 1. Serial coronary angiograms (a right anterior oblique view) before and after histamine administration in a pig $3 \mathrm{mo}$ after endothelial denudation of the left anterior descending artery. After intracoronary (IC) administration of histamine ( $3 \mu \mathrm{g} /$ $\mathrm{kg}$ ), coronary spasm (large arrow) associated with delayed filling (small arrows) was provoked at the previously denuded site. Electrocardiogram showed ST segment elevation in $V_{1}$ lead, when spasm was provoked. contraction, and no statistical difference in the dose-response relationship for either $\alpha$ agonist was found between the denuded and nondenuded muscles. Increased sensitivity to histamine was noted at the denuded site compared with the nondenuded site, as manifested by significantly lower $\mathrm{pD}_{2}$ values for the former. The maximal response to histamine was larger in denuded muscles than nondenuded ones. After removal of the endothelium, contractile responses to these $\alpha$ agonists were not statistically changed, but those to histamine were further augmented. In contrast, cocaine in concentrations from $10^{-7}$ to $3 \times 10^{-3} \mathrm{M}$ did not produce any active force in muscles from denuded or nondenuded sites. A contractile response was not

Table II. Effects of Cocaine on CSA of the Denuded (LAD) and Nondenuded (LCX) Vessels

\begin{tabular}{|c|c|c|c|c|}
\hline & \multicolumn{2}{|c|}{ Percent reduction in CSA } & \multirow[b]{2}{*}{ MAP } & \multirow[b]{2}{*}{ HR } \\
\hline & $\begin{array}{l}\text { Denuded site } \\
\text { (LAD) }\end{array}$ & $\begin{array}{l}\text { Nondenuded site } \\
\quad(\text { LCX) }\end{array}$ & & \\
\hline & & & $m m H g$ & bpm \\
\hline \multicolumn{5}{|c|}{ Before endothelial denudation } \\
\hline Baseline & $10 \pm 2$ & $8 \pm 2$ & $94 \pm 4$ & $102 \pm 5$ \\
\hline \multicolumn{5}{|l|}{ Cocaine } \\
\hline $1 \mathrm{mg} / \mathrm{kg}(n=6)$ & $19 \pm 1^{*}$ & $22 \pm 2^{*}$ & $109 \pm 5^{*}$ & $96 \pm 5$ \\
\hline $3 \mathrm{mg} / \mathrm{kg}(n=6)$ & $38 \pm 2^{\ddagger}$ & $32 \pm 2^{\ddagger}$ & $116 \pm 4^{\ddagger}$ & $112 \pm 6^{*}$ \\
\hline $10 \mathrm{mg} / \mathrm{kg}(n=8)$ & $43 \pm 2^{\ddagger}$ & $44 \pm 2^{\ddagger}$ & $122 \pm 6^{\ddagger}$ & $126 \pm 5^{\ddagger}$ \\
\hline \multicolumn{5}{|c|}{3 mo after endothelial denudation } \\
\hline Baseline & $10 \pm 1$ & $12 \pm 1$ & $89 \pm 4$ & $110 \pm 4$ \\
\hline \multicolumn{5}{|l|}{ Cocaine } \\
\hline $1 \mathrm{mg} / \mathrm{kg}(n=8)$ & $23 \pm 2 *$ & $20 \pm 1^{*}$ & $104 \pm 4^{*}$ & $107 \pm 5$ \\
\hline $3 \mathrm{mg} / \mathrm{kg}(n=8)$ & $40 \pm 2^{\ddagger}$ & $34 \pm 1^{\ddagger}$ & $128 \pm 6^{\ddagger}$ & $130 \pm 6^{\ddagger}$ \\
\hline $10 \mathrm{mg} / \mathrm{kg}(n=8)$ & $59 \pm 1^{* \S}$ & $48 \pm 2^{\ddagger}$ & $130 \pm 6^{\ddagger}$ & $130 \pm 4^{\ddagger}$ \\
\hline
\end{tabular}

Data are means \pm SEM. Percent changes in CSA in response to cocaine are shown. Abbreviations are same as in Table I. ${ }^{*} P<0.05 ; \ddagger P<0.01$ vs. baseline. ${ }^{s} P<0.05$; vs. nondenuded site (LCX) by two-way ANOVA plus a Bonferroni test with 10 pairwise comparisons. 
CONTROL ANGIOGRAM
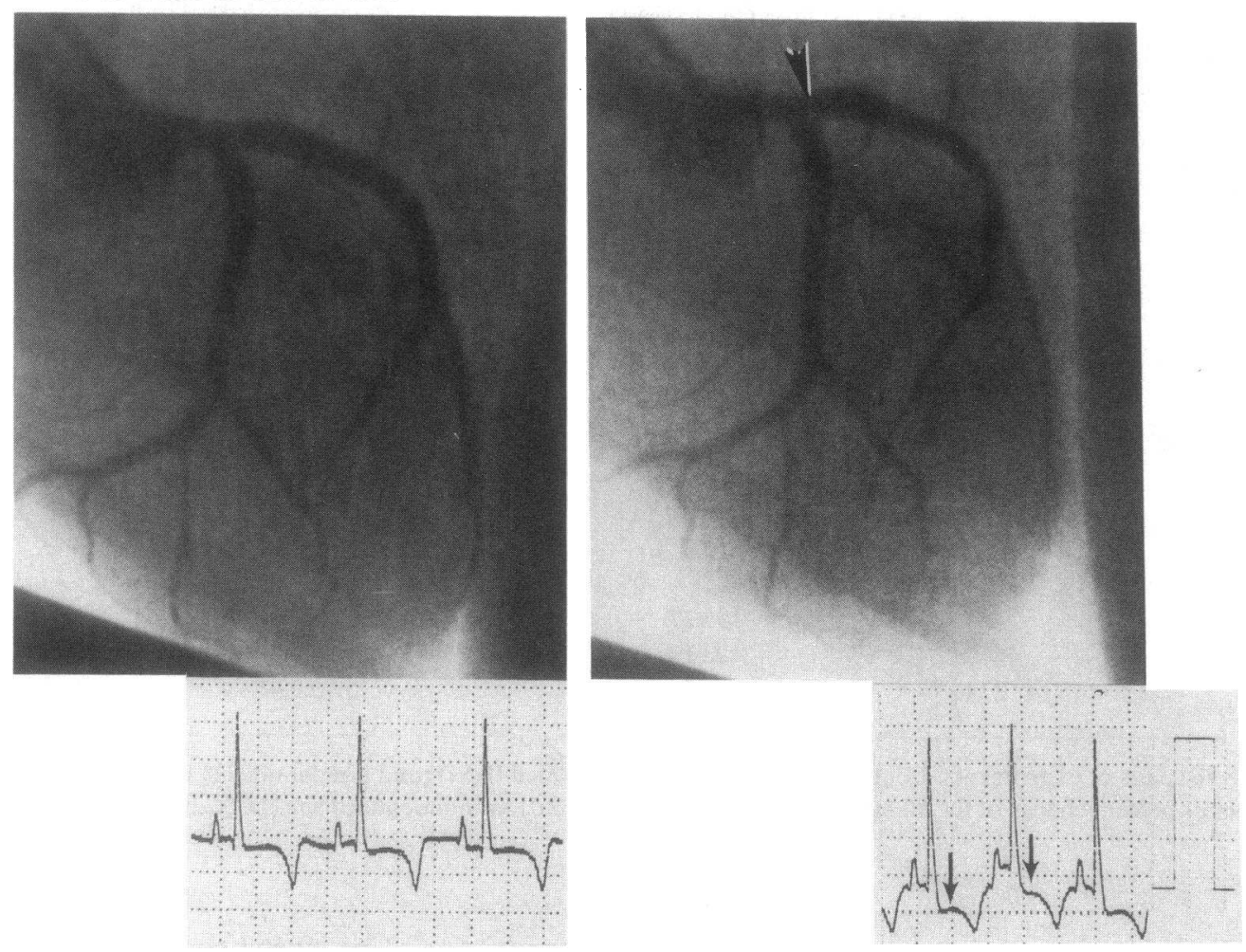

\section{AFTER COCAINE IV}

Figure 2. Serial coronary angiograms before and after intravenous (IV) cocaine $(10 \mathrm{mg} / \mathrm{kg})$ in the same pig presented in Fig. 1. After cocaine, luminal narrowing of the proximal LAD (previously denuded site as is indicated by an arrow) is greater than that of similar anatomical portion of LCX. detected even after removal of endothelium or pretreatment with propranolol $10^{-7} \mathrm{M}$. Instead, high concentrations $\left(10^{-3}\right.$ $\mathrm{M})$ of cocaine decreased tension in some preparations.

Histologic study. Myointimal thickening that was covered with the regenerated endothelium, was microscopically evident at the previously denuded site, as previously described $(6,7)$. These changes were not observed in the nondenuded vessels.

\section{Discussion}

A putative link between the abuse of cocaine and the occurrence of coronary vasospasm is at the best speculative at the present time. Accordingly, the present study was performed to determine the effects of cocaine on vasoconstrictor responses in the swine model of coronary vasospasm. On the basis of our
BEFORE ENDOTHELIAL DENUDATION

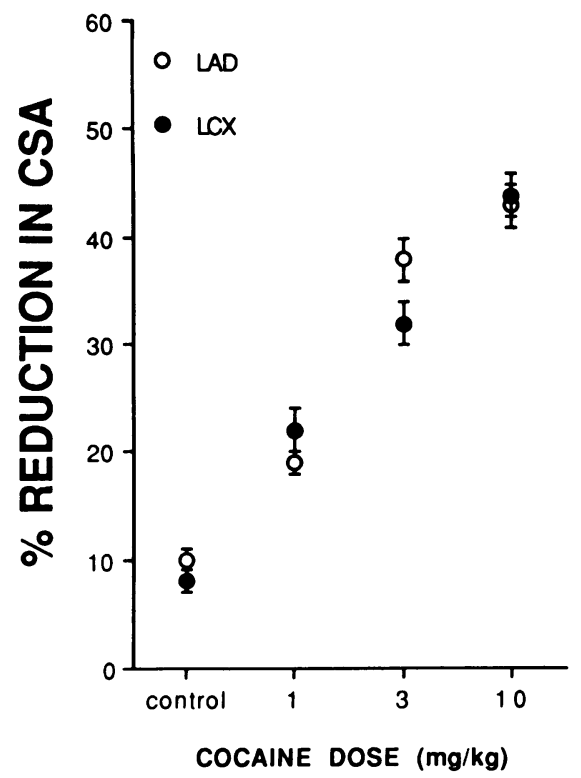

3 MONTHS AFTER ENDOTHELIAL DENUDATION

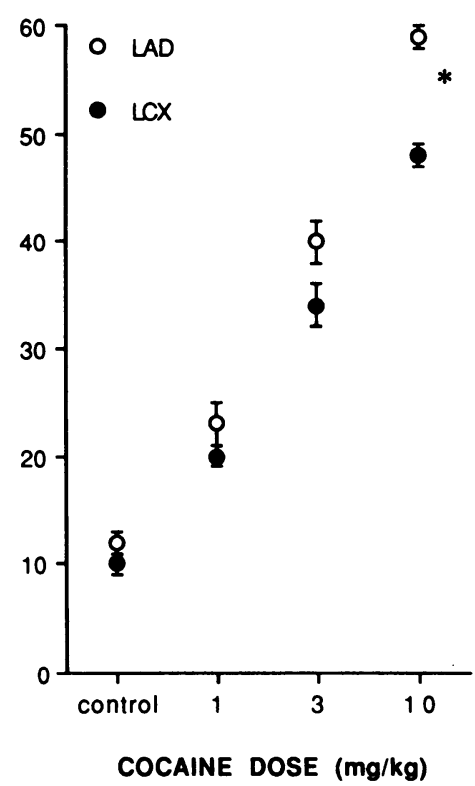

Figure 3. Summary of percent changes in CSA of the LAD (denuded site) and the LCX (nondenuded site) after cocaine administration. Before endothelial denudation (left), responses of the LAD and LCX to cocaine $(1,3$, and $10 \mathrm{mg} / \mathrm{kg}$ ) are identical. At 3 mo after the denudation (right), constrictive response of the LAD to cocaine dosage is significantly larger than that of $\operatorname{LCX}(P<0.01$ by two-way ANOVA and by multiple linear regression analysis). ${ }^{*} P<0.05$ between the LAD and LCX by ANOVA plus Bonferroni test. 


\begin{tabular}{|c|c|c|c|c|}
\hline & \multicolumn{2}{|c|}{$\begin{array}{c}\text { Maximal force } \\
\left(10^{5} \times \mathrm{N} / \mathrm{m}^{2} \text { or percent change }\right) \\
\end{array}$} & \multicolumn{2}{|c|}{$\begin{array}{c}\mathrm{pD}_{2} \\
{\left[-\log \left(\mathrm{ED}_{\left.\left.\mathbf{s o}_{0}\right)\right]}\right.\right.}\end{array}$} \\
\hline & LAD & LCX & LAD & LCX \\
\hline \multicolumn{5}{|l|}{ Experiments in vessels with endothelium } \\
\hline Resting force & $0.4 \pm 0.1$ & $0.4 \pm 0.1\left(10^{5} \times \mathrm{N} / \mathrm{m}^{2}\right)$ & - & - \\
\hline Active contraction by $60 \mathrm{mM} \mathrm{KCl}$ & $0.7 \pm 0.1$ & $0.7 \pm 0.1\left(10^{5} \times \mathrm{N} / \mathrm{m}^{2}\right)$ & - & - \\
\hline \multicolumn{5}{|l|}{ Active contraction by } \\
\hline Cocaine HCL & $0 \%$ & $0 \%$ & - & - \\
\hline Methoxamine & $20 \pm 4 \%$ & $18 \pm 2 \%$ & $5.0 \pm 0.2$ & $4.9 \pm 0.2$ \\
\hline BHT-920 & $15 \pm 2 \%$ & $12 \pm 1 \%$ & $5.2 \pm 0.1$ & $4.9 \pm 0.2$ \\
\hline Histamine & $198 \pm 7 \%^{*}$ & $104 \pm 8 \%$ & $5.6 \pm 0.2^{*}$ & $4.8 \pm 0.2$ \\
\hline \multicolumn{5}{|c|}{ Experiments in vessels without endothelium } \\
\hline Resting force & $0.4 \pm 0.1$ & $0.4 \pm 0.1\left(10^{5} \times \mathrm{N} / \mathrm{m}^{2}\right)$ & - & - \\
\hline Active contraction by $60 \mathrm{mM} \mathrm{KCl}$ & $0.8 \pm 0.1$ & $0.9 \pm 0.1\left(10^{5} \times \mathrm{N} / \mathrm{m}^{2}\right)$ & - & - \\
\hline \multicolumn{5}{|l|}{ Active contraction by } \\
\hline Cocaine HCL & $0 \%$ & $0 \%$ & - & - \\
\hline Methoxamine & $24 \pm 2 \%$ & $19 \pm 2 \%$ & $5.1 \pm 0.3$ & $5.0 \pm 0.2$ \\
\hline BHT-920 & $15 \pm 2 \%$ & $12 \pm 1 \%$ & $5.3 \pm 0.2$ & $5.0 \pm 0.2$ \\
\hline Histamine & $224 \pm 9 \% *$ & $132 \pm 7 \%$ & $5.9 \pm 0.4^{*}$ & $4.9 \pm 0.3$ \\
\hline
\end{tabular}

Data are mean \pm SEM obtained from 8-10 pairs of experiments. Contractile responses of the denuded (LAD) and nondenuded (LCX) coronary arteries are presented as absolute values or percent change of the $60 \mathrm{mM} \mathrm{KCl}$ contraction. ${ }^{*} P<0.01$ vs. nondenuded site (LCX) by Student's $t$ test.

initial findings (Fig. 1 and Table I), we are convinced that we succeeded in establishing a model of coronary vasospasm comparable to that previously described (6-10). These findings confirm results of recent clinical and experimental studies suggesting an important role of atherosclerotic change in the arterial wall as a leading factor in creating the milieu for vasospasm to occur (13-20).

Effects of cocaine in the swine model. The most important finding of this study is that $\mathbf{3}$ mo after endothelial denudation constrictive responses to cocaine were significantly enhanced at the denuded LAD site compared with the nondenuded LCX site. Responsiveness of the nondenuded site was not changed during the 3-mo period. These data show that, in response to cocaine, the denuded coronary artery segments constricted to a greater degree than control segments in vivo. By histologic examination, myointimal thickening was evident at the level of endothelial denudation. Injury of vascular endothelial cells is generally recognized as an initial event leading to atherosclerosis (21). These findings suggest that an atherosclerotic process played an important role in the pathogenetic mechanism underlying cocaine-induced hypercontraction.

Electrocardiographic ST depression occurred coincidentally with cocaine-induced hypercontraction at the $10 \mathrm{mg} / \mathrm{kg}$ dose in all eight pigs; however, it also occurred before endothelial denudation in six of eight pigs. It is generally believed that myocardial perfusion would not be critically jeopardized until more than $90 \%$ reduction of cross-sectional area of epicardial vessels occurs (22). Therefore, the causal relationship between cocaine-induced epicardial coronary hypercontraction (up to $59 \pm 5 \%$ area reduction) and significant $\mathrm{ST}$ depression appears to be obscure in the absence of hemodynamic, functional, or bislogical evidence of myocardial ischemia. An alternative interpretation is that ischemic ST depression was produced by the drug-induced constriction of peripheral coronary vessels (23). Further studies will be required to elucidate cocaine's effects on peripheral coronary vessels.

Potential causes of cocaine-induced coronary vasoconstriction. Despite angiographical evidence that cocaine produced epicardial coronary vasoconstriction in vivo, cocaine in concentrations up to $3 \times 10^{-3} \mathrm{M}$ surprisingly did not produce any active contraction of isolated control or spastic arteries in vitro. Those vascular tissues responded to histamine or $\alpha$ agonists by generating reasonable levels of contraction, indicating that the functional integrity of agonist receptors on the cell membrane is preserved. These results suggest the possibility that cocaine by itself did not evoke a contractile response in our preparation. These data are compatible with results in human coronary arteries from patients with end-stage heart failure (24) and a preliminary communication in the porcine coronary arteries (25), but differ from studies in rabbit aorta (26), rat tail artery (27), and guinea-pig portal vein (28), showing that cocaine produced contractile responses. These contrasting results on the vascular effects of cocaine may depend on the difference of the density and/or distribution of adrenergic receptors and sympathetic innervation among the species or vascular beds studied. According to these findings, it appears plausible to conclude that cocaine-induced porcine coronary arterial constriction, which occurred under in vivo conditions, was caused by secondary release of humoral and/or neural vasoactive substances, but not by direct actions of the drug on the coronary arterial smooth muscle.

Cocaine is an agent that exerts marked sympathomimetic actions, which are expected to cause alpha adrenergic vasoconstriction (29). Our result that cocaine-induced constriction decreased after $\alpha_{1}$ blockade with bunazosin suggests that cocaineinduced constriction of intact (i.e., nonatherosclerotic) coro- 
nary arteries is mediated, at least in part, by $\alpha_{1}$ adrenoceptor stimulation in vivo. However, mechanisms other than alpha adrenoceptor stimulation appear to play a role in causing cocaine-induced hypercontraction, because in the presence of $\alpha_{1}$ blockade the percent area reductions by cocaine were still statistically different between denuded and nondenuded vessels. This consideration was confirmed by our in vitro experiments showing that contractile responses to $\alpha_{1}$ or $\alpha_{2}$ receptor agonists were not statistically different between preparations from the denuded and nondenuded sites. In this regard, well-designed clinical studies did not support adrenergically mediated vasoconstriction as a primary cause of coronary vasospasm (3032). It remains to be determined, however, if the neovascularization, or an alteration in neuronal metabolism of catecholamines, either of which may occur in atherosclerotic regions, and in turn, increase local levels of catecholamines (33), might contribute to the cocaine-induced hypercontraction.

Results of the present study showed that cocaine does not appear to alter vascular tone by acting directly on the endothelium. These data are compatible with in vitro studies by Rongione et al. (26). However, it may be possible that atherosclerotic vessels would respond by contraction to neurohumoral factors, such as norepinephrine or platelet factors, that may be released by cocaine's indirect actions. It is important to note that impaired endothelium-dependent relaxation to neuro-humoral factors has been demonstrated in atherosclerotic vessels $(17,18)$.

Available data indicate that cocaine can increase platelet aggregability and decrease endothelial prostacyclin production in vitro (34). These effects, if demonstrated under in vivo conditions, would enhance the intravascular production of vasoconstrictors such as serotonin or thromboxane $A_{2}$, decrease the prostacyclin/thromboxane $A_{2}$ ratio, and induce fibrin clotting. These various events could be accelerated in regions with atherosclerotic vessels (35). Therefore, we speculate that vasoreactivity to cocaine could secondarily be augmented if cocaine is an agent that participates in these various vascular events. Thus, modification of the interaction between blood components and the coronary arterial wall by cocaine requires further study.

Conclusions and clinical implications. We have demonstrated the reactivity of epicardial coronary arteries to cocaine is enhanced at the level of previous endothelial injury in the swine model; this is a unique result which has several important clinical implications. First, we believe that this report is the first one to shed light on a putative link between cocaine use and coronary vasospasm. The dose $(10 \mathrm{mg} / \mathrm{kg})$ that evoked the enhanced contractile response to cocaine in this study appears to be comparable to the amount of drug used by patients with drug-associated myocardial infarction (3). In this regard, Flores et al. (36) have recently published data from patients with coronary artery disease demonstrating that intranasal cocaine causes enhanced vasoconstriction at sites of atherosclerotic narrowing of the large epicardial coronary artery. However, it remains to be determined if other factors besides coronary vasospasm mediate development of cocaine's cardiac toxicity, including cardiomyopathy (37). These factors could indicate release of catecholamines from nerve endings or a direct action of cocaine on myocardial or vascular receptors. Second, the clinical relevance of our data is demonstrated by the observation that cocaine abusers with documented ischemic heart disease have variable degrees of atherosclerotic coronary artery disease $(3,4)$. In this regard, there is experimental evidence showing that repeated treatment with cocaine resulted in damage of arterial tissue leading to formation of atherosclerotic lesions (38).

\section{Acknowledgments}

The authors are grateful to William Grossman of Beth Israel Hospital and James Ross of Tufts School for their encouragement of this work, and Jason Kravitz for typing this manuscript.

This study was supported by grants DA-05171 from the National Institute of Drug Abuse, Rockville, MD, and HL-31117 and HL-01611 from the National Institutes of Health, Bethesda, MD, and a grant-inaid from the Mochida Memorial Foundation for Medical Research, Tokyo, Japan.

\section{References}

1. Gawin, F. H., and E. H. Ellinwood, Jr. 1988. Cocaine and other stimulants. N. Engl. J. Med. 318:1173-1182.

2. Cregler, L. L., and H. Mark. 1986. Medical complication of cocaine abuse. N. Engl. J. Med. 315:1495-1500.

3. Isner, J. M., N. A. M. Estes, P. D. Thompson, M. R. Costanzo-Nordin, R. Subramanian, G. Miller, G. Katsas, K. Sweeney, and W. Q. Sturner. 1986. Acute cardiac events temporally related to cocaine abuse. $N$. Engl. J. Med. 315:14381443.

4. Smith, H. W. B., H. A. Liberman, S. L. Brody, L. L. Battey, B. C. Donohue, and D. C. Morris. 1987. Acute myocardial infarction temporally related to cocaine use. Ann. Intern. Med. 107:13-18.

5. Lange, R. A., R. G. Cigarroa, C. W. Yancy, Jr., J. E. Willard, J. J. Popma, M. N. Sillis, W. McBride, A. S. Kim, and L. D. Hillis. 1989. Cocaine-induced coronary artery vasoconstriction. N. Engl. J. Med. 321:1557-1562.

6. Shimokawa, H., H. Tomoike, S. Nabeyama, H. Yamamoto, H. Araki, and M. Nakamura. 1983. Coronary artery spasm induced in atherosclerotic miniature swine. Science (Wash. DC). 221:560-562.

7. Egashira, K., H. Tomoike, Y. Yamamoto, A. Yamada, Y. Hayashi, and M. Nakamura. 1986. Histamine-induced coronary spasm on regions of intimal thickening in miniature pigs. Circulation. 74:826-837.

8. Tomoike, H., K. Egashira, A. Yamada, Y. Hayashi, and M. Nakamura. 1987. Leuokotriene C4 and D4 induced diffuse peripheral constriction of swine coronary artery accompanied by ST elevation on the electrocardiogram. Circulation. 76:480-487.

9. Yamamoto, Y., H. Tomoike, K. Egashira, and M. Nakamura. 1987. Attenuation of endothelium-related relaxation and enhanced responsiveness of vascular smooth muscle to histamine in spastic coronary arterial segments from miniature pigs. Circ. Res. 61:772-778.

10. Tomoike, H., K. Egashira, Y. Yamamoto, and M. Nakamura. 1989. Enhanced responsiveness of smooth muscle, impaired endothelium-dependent relaxation and the genesis of coronary spasm. Am. J. Cardiol. 63:33E-39E.

11. Glantz, S. A., and B. K., Slinker. 1990. Primer of applied regression and analysis of variance. McGraw-Hill Book Co., Inc., New York. 272-380.

12. Slinker, B. K., and S. A. Glantz. 1990. Missing data in two way analysis of variance. Am. J. Physiol. 258(Regul. Integrative Comp. Physiol. 27):R291-R297.

13. Hillis, L. D., and E. Braunwald. 1978. Coronary artery spasm. N. Engl. J. Med. 299:695-702.

14. Maseri, A., and S. Chierchia. 1982. Coronary artery spasm: demonstration, definition, diagnosis and consequences. Prog. Cardiovasc. Dis. 25:162-192. 15. Nakamura, M. 1985. Myocardial ischemia. Jpn. Circ. J. 49:1-12.

16. Ginsburg, R., M. R. Bristow, K. Davis, A. Divase, and M. E. Billingham. 1984. Quantitative pharmacologic responses of normal and atherosclerotic isolated human coronary arteries. Circulation. 69:430-440.

17. Vanhoutte, P. M., and H. Shimokawa. 1989. Endothelium-derived relaxing factor and coronary vasospasm. Circulation. 80:1-9.

18. Young, M. A., and S. F. Vatner. 1986. Regulation of large coronary arteries. Circ. Res. 59:579-596.

19. Heistad, D. D., M. L. Armstrong, M. L. Marcus, D. J. Piegors, and A. L. Mark. 1984. Augmented responses to vasoconstrictor stimuli in hypercholesterolemic and atherosclerotic monkeys. Circ. Res. 54:711-718.

20. Henry, P. D., and M. Yokoyama. 1980. Supersensitivity of atherosclerotic rabbit aorta to ergonovine: mediation by serotonergic mechanism. J. Clin. Invest. 66:306-313.

21. Ross, R. 1986. The pathogenesis of atherosclerosis-an update. N. Engl. J. Med. 314:488-500.

22. Gould, K. L., and K. Lipscomb. 1974. Effects of coronary stenosis on coronary flow reserve and resistance. Am. J. Cardiol. 34:48-55. 
23. Hale, S. L., K. J. Alker, S. Rezkalla, G. Figures, and R. A. Kloner. 1989. Adverse effects of cocaine on cardiovascular dynamics, myocardial blood flow, and coronary artery diameter in an experimental model. Am. Heart J. 118:927933.

24. Perreault, C. L., P. D. Allen, N. Hague, K. G. Morgan, and J. P. Morgan. 1989. Differential mechanisms of cocaine-induced depression of contractile function in cardiac and vascular smooth muscle. Circulation. 80(Suppl. II):15, (Abstr.)

25. Vargas, R., Z. Zukowska-Grojec, R. A. Gillis, and P. W. Ramwell. 1988. Cocaine and coronary artery reactivity. Circulation. 78:II-223. (Abstr.)

26. Rongione, A. J., G. Steg, D. Gal, and J. M. Isner. 1988. Cocaine causes endothelium-independent vasoconstriction of vascular smooth muscle. Circulation. 78:II-436. (Abstr.)

27. Webb, R. C., P. M. Vanhoutte, and D. F. Bohr. 1980. Inactivation of released norepinephrine in rat tail artery by neuronal uptake. J. Cardiovasc. Pharmacol. 2:121-132.

28. O'Connor, P. C., and P. Slater. 1981. Effects of cocaine on noradrenaline contractions of mesenteric vein: pre- or postjunctional mechanism? J. Pharm. Pharmacol. 33:58-60.

29. Ritchie, J. M., and N. M. Greene. 1985. Local anesthetics. In A. G. Gilman, L. S. Goodman, T. W. Rall, and F. Murad, editors. The Pharmacological Basis of Therapeutics. 7th Edition. Macmillan, New York. 302-321.

30. Feigl, E. O. 1987. The paradox of adrenergic coronary constriction. Circulation. 76:737-745.
31. Winniford, M. D., N. Filipchuk, and L. D. Hillis. 1983. Alpha-adrenergic blockade for variant angina. Circulation. 67:1185-1188.

32. Chierchia, S., G. Davis, G. Berkenboom, F. Crea, P. Crean, and A. Maseri. 1984. Alpha-adrenergic receptors and coronary spasm: An elusive link. Circulation. 69:8-14.

33. Barger, A. C., R. Beeuwkes II, L. L. Lainey, and K. J. Silverman. 1984. Hypothesis: vasa vasorum and neovascularization of human coronary arteries. A possible role in the pathophysiology of atherosclerosis. N. Engl. J. Med. 310:175177.

34. Togna, G., E. Tempesta, A. R. Togan, N. Dolci, B. Abo, and L. Caprino. 1985. Platelet responsiveness and biosynthesis of thromboxane and prostacyclin in response to in vitro cocaine treatment. Haemostasis. 15:100-107.

35. Willerson, J. T., L. D. Hillis, M. Winniford, and L. M. Buja. 1986. Speculation regarding mechanisms responsible for acute ischemic heart disease syndromes. J. Am. Coll. Cardiol. 8:245-250.

36. Flores, E. D., R. A. Lange, R. G. Cigarroa, and L. D. Hillis. 1990. Effect of cocaine on coronary artery dimensions in atherosclerotic coronary artery disease: enhanced vasoconstriction at sites of significant stenosis. J. Am. Coll. Cardiol. 16:74-79.

37. Wiener, R. S., J. T. Lockhart, and R. G. Schwartz. 1986. Dilated cardiomyopathy and cocaine abuse. Am. J. Med. 81:699-701.

38. Langner, R. O., C. L. Bement, and L. E. Perry. 1988. Atherosclerotic toxicity of cocaine. Natl. Inst. Drug Abuse Monogr. Ser. 88:323-336. 